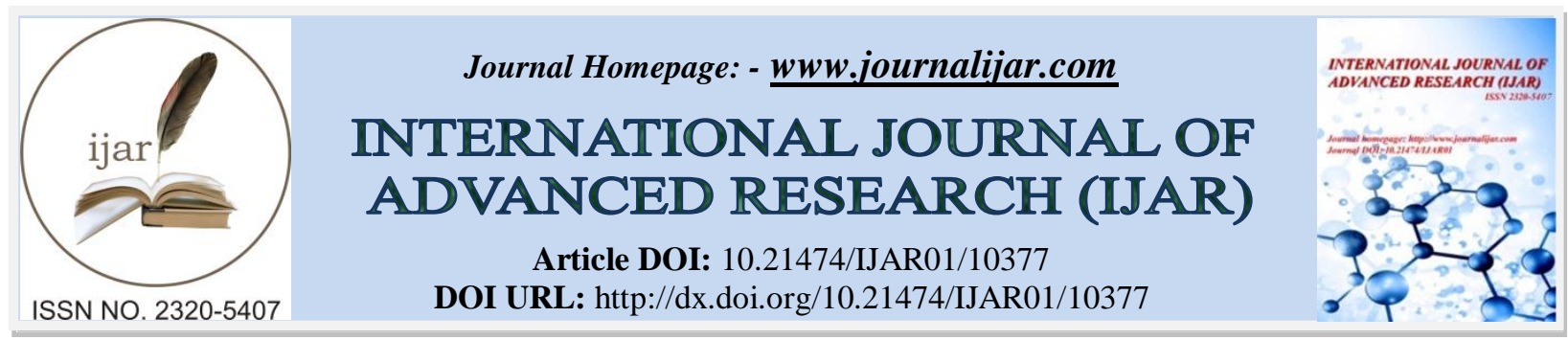

RESEARCH ARTICLE

\title{
PREVALENCE STUDY OF SPINAL DEFORMITIES IN SCHOOL GOING CHILDREN OF THE AGE GROUP OF 6-10 YEARS IN A RURAL AREA
}

\author{
Richa Lahiri ${ }^{1}$ and Dr. Pradeep Borkar $(\mathbf{P T})^{2}$ \\ 1. Intern, Dr. A.P.J. Abdul Kalam College of Physiotherapy, Loni, Maharashtra, India. \\ 2. Assistant Professor, Dr. A.P.J. Abdul Kalam College of Physiotherapy, Loni, Maharashtra, India.
}

\section{Manuscript Info}

..........................

Manuscript History

Received: 30 November 2019

Final Accepted: 31 December 2019

Published: January 2020

Key words:-

Prevalence, Spinal Deformity, School Going Children, Flexicurve, Rural Area

\section{Abstract}

Objective: To identify whether spinal deformities are prevalent in school going children of the age group 6-10 years in a rural area.

Methodology: The study involved 100 students between the age group of 6-10 years from a rural area. The participants were assessed for the presence of spinal deformities in the sagittal plane for cervical, thoracic and lumbar spine.

Outcome Measure: Flexicurve instrument was used for the purpose of assessment of the spinal deformities.

Result: The data revealed that there was $21 \%$ of prevalence of forward head posture whereas $20 \%$ had decreased cervical curvature. For the thoracic spine, 5\% had thoracic hyperkyphosis and 20\% had thoracic hypokyphosis whereas for the lumbar spine, $54 \%$ of the participants had lumbar hyperlordosis and $1 \%$ had lumbar hypolordosis.

Conclusion: The percentage of presence of spinal deformities indicated that there is a need for awareness about the spinal deformities and its effects as well as a need to reinforce the importance of good posture since an early age.

Copy Right, IJAR, 2020,. All rights reserved.

\section{Introduction:-}

Physical development of children is related to their physical growth regime, early detection, prevention and treatment of diseases that accompany growth. From an early age the posture of man undergoes significant changes. Most of them are pronounced during preschool and school age. Most common diseases during childhood and adolescence ages include postural disorders and spinal deformities. ${ }^{[1]}$

The Posture Committee of the American Academy of Orthopedic Surgeons defines posture as "Posture is usually defined as the relative arrangement of the parts of the body."[2] Body posture is affected by socioeconomic, structural, surroundings, and communicative factors, separately or combined, and this can create different results even for a population of students with resemblances in age and body mass index (BMI), which makes it hard for comparison of different places and environments. ${ }^{[3]}$

Spinal deformity is defined as a curvature in the spine where the arrangement is outside of defined normal limits. ${ }^{[4]}$ Spinal deformity can be either functional or structural. Structural deformities are rigid and inflexible whereas functional deformities are in response to structural deformities as the body's attempt to maintain its posture. Abnormal curvature of the spine may be in sagittal plane which may be Forward neck, Thoracic Kyphosis and

Corresponding Author:- Richa Lahiri

Address:- Intern, Dr. A.P.J. Abdul Kalam College of physiotherapy, Loni, Maharashtra, India. 
Lumbar lordosis or in the coronal plane that is scoliosis. Abnormal curvatures in the sagittal plane causes imbalance to the person's front or back and when in the coronal plane it causes imbalance in to the person's right or left side. ${ }^{[4]}$ The reason is a reduced mechanical activity, long hours of staying in front of the computer from early age, bad posture at school, heavy backloads, unhealthy diet, increased traumatic injuries, congenital spinal abnormalities. ${ }^{\text {[3] }}$ Apart from these, if a bad posture is taken up by a child they may keep repeating it which ultimately leads to fatigue and changes in the musculature of the spine.

Children between the age of 6-7 years are in a critical period of posture-genesis. (Cordon et al., 2002). ${ }^{[5]}$ There are many morphological and functional changes between the ages of 7-14 years which influence the regular posture of the spinal column and so in this period active corrective exercises of appropriate programs should be performed. ${ }^{[5]}$

Early detection, correct diagnosis, appropriate treatment and rehabilitation, prevention, appropriate active exercise protocol, all can prevent adverse effects of the postural disorders and spinal deformities which will in turn ensure the smooth functioning of an adolescent man. ${ }^{[1]}$

Spine evaluation is important both for monitoring and to diagnose vertebral alterations. ${ }^{[6]}$ A variety of methods have been used to assess spinal deformities. Some are conventional, while some are latest and few are those which got modified into latest form from conventional forms i.e. these evolved into better and convenient methods. ${ }^{[7]}$. Posture can be assessed using various methods like a plumb line, photography, photogrammetry, radiography, flexicurve, moire topography and an electromagnetic tracking device. ${ }^{[8]}$

The "gold standard" method that exists as of now is the radiographic method ${ }^{[7]}$ but it entails exposure to undesirable radiation levels, so non-invasive methods have great advantage because of their lower cost, fewer technical problems and the absence of exposure to ionizing radiation. ${ }^{[6]}$ The commonest method which is used to evaluate posture is the visual observation method, since it does not involve any equipment. With this method, quantitative data cannot be obtained, minor postural changes cannot be analyzed and it has a poor inter-rater agreement. All these restrictions discourage the use of this method for research purposes. ${ }^{[7]}$ Among the non-invasive methods is the Flexicurve, a flexible ruler that was first described by Takahashi and Atsumi. ${ }^{[6]}$ The Flexicurve allows measurements in the sagittal plane and can be used in several surroundings and its seen as a cheap and quick evaluation instrument.

[6] The Flexicurve instrument can be a screening tool because it is easily available and handy for the school environment. ${ }^{[6]}$

\section{Need for the study:-}

In the beginning, deviations in normal posture are functional, but due to lack of proper modification, permanent structural changes, especially in the spine, ensue (Popov (Попов), 2006). ${ }^{[1]}$ Many authors stated that starting the conservative management early can prevent the progress of severe deformity and avoid surgery (Focarile, Bonaldi\&Giarolo, 1991); (Fernandez-Filiberty, Flinn\&Ramires, 1995); (Haher, Merola, Zipnick\&Gorup, 1995); (Halm, Castro, Jerosch\&Winkelmann, 1995). [1] Awareness about the spinal deformities, its effect on the life of a child and its treatment is necessary. Hence, this study is needed to study the prevalence of spinal deformities in primary school going children in rural area.

\section{Research question:-}

Is there any prevalence of spinal deformities in school going children in the age group of 6-10 years in a rural area?

\section{Aim of the study:-}

To study the prevalence of spinal deformities in school going children of age group of 6-10 years in a rural area.

\section{Primary objective of the study:-}

To identify whether spinal deformities are prevalent in school going children of the age group 6-10 years in a rural area.

\section{Secondary objective of the study:-}

To assess the spinal deformities in school going children of the age group of 6-10 years in a rural area. 


\section{Methodology:-}

Source of Data: Data was collected from Pravara Kanya Vidya Mandir, Pravara Girls New English School, Zilha Parishad School and Brilliant Bird School in Loni, Ahmednagar.

Method of collection of Data:

Primary data was collected by principal investigator

\section{Study Design:}

Descriptive Survey

\section{Sample size:}

100 Subjects

\section{Sampling Method:-}

Simple random sampling

\section{Study Duration:}

5 months.

\section{Equipments used:}

Flexicurve

\section{Materials used:}

Graph paper, marking tape

\section{Selection criteria:-}

\section{Inclusion criteria:}

1. Male and female school going children.

2. Age group of 6-10 years

3. Those willing to participate.

\section{Exclusion criteria:}

1. Participants with recent injuries or illnesses.

\section{Procedure:-}

Ethical clearance was obtained from Institutional Ethical Committee of Dr. A.P.J. Abdul Kalam College of Physiotherapy, PIMS-DU. The sample of subjects comprised of 100 children of the age between 6-10 years, out of which 34 were females and 66 were males. It was conducted in 4 schools in Loni, Ahmednagar. The four schools were Pravara Kanya Vidya Mandir School, Pravara Girls New English School, Brilliant Bird School and Zilha Parishad School. Permission was taken from the school to conduct the study. A total of 100 students were selected randomly out of 1375 . Written informed consent was taken from the subject's parent or guardian before conducting the study.

The subjects were submitted to a postural evaluation with the help of a flexicurve instrument which provided the flexicurve angles for the cervical, thoracic and lumbar spine. The same protocol was repeated in each evaluation: (1) On the child's bare back, anatomical points which are C0, C1, C2, C7, T1, T2, T12, L1, L5 and S1 were palpated and marked with the help of stickers; (2) the child was in the standing position with normal posture; (3) the child was asked to stay motionless; (4) the Flexicurve was molded to the child's back over the spine; (5) the Flexicurve was removed from the child's back and placed on the graph paper where the curvature was drawn and the anatomical points were marked; and (6) the Flexicurve angle was obtained using Biomec-FLEX free software (www.ufrgs.br/biomec), in which the input data consisted of the co-ordinate values representing the cervical, the thoracic and lumbar curvatures, and the output data consisted of the curvature angles in sagittal plane. 


\section{Outcome Measures:-}

\section{Flexicurve:}

It is a device which bends in one plane only and can maintain a fixed shape that can be transferred to paper. The flexicurve is placed over the spinous processes of the cervical, thoracic and lumbar spine and shaped according to these spinal curves. The instrument is carefully removed and traced onto a piece of plain white paper. The convex side of the curve's outline is traced on a piece of poster board. The quantification of the curve can be done by either tangent method or trigonometric method. The flexicurve angle and index showed excellent intra rater(ICC $=0.94)$ and good inter rater(ICC $=0.86)$ reliability. ${ }^{[9]}$

\section{Data analysis and results:-}

A total of 100 participants were selected from four schools according to the total number of students in a school. The cervical, thoracic and lumbar curvature angles of the participants were obtained. The prevalence of spinal deformities was obtained on the basis of these angles.

\section{Demographic data:}

The average age of the participants was 7.61 \pm 1.34 years and 66 of them were males and 34 of them were females.

\begin{tabular}{|l|l|}
\hline Demographic characteristics & Values \\
\hline Age (years) & $7.61 \pm 1.34$ \\
\hline $\begin{array}{l}\text { Gender } \\
\text { (F:M) }\end{array}$ & $34: 66$ \\
\hline
\end{tabular}

Table no. 1:- Distribution of participants in angle ranges for cervical curvature.

\begin{tabular}{|l|l|}
\hline Angle Ranges & No. of participants \\
\hline$<20^{0}$ & 2 \\
\hline $20^{0}-24.9^{0}$ & 8 \\
\hline $25^{0}-29.9^{0}$ & 10 \\
\hline $30^{0}-34.9^{0}$ & 34 \\
\hline $35^{0}-39.9^{0}$ & 25 \\
\hline$>40^{0}$ & 21 \\
\hline Total & 100 \\
\hline Mean angle \pm Standard Deviation & $35.19^{0} \pm 6.56^{0}$ \\
\hline
\end{tabular}

Graph no. 1:- Distribution of participants in angle ranges for cervical curvature.

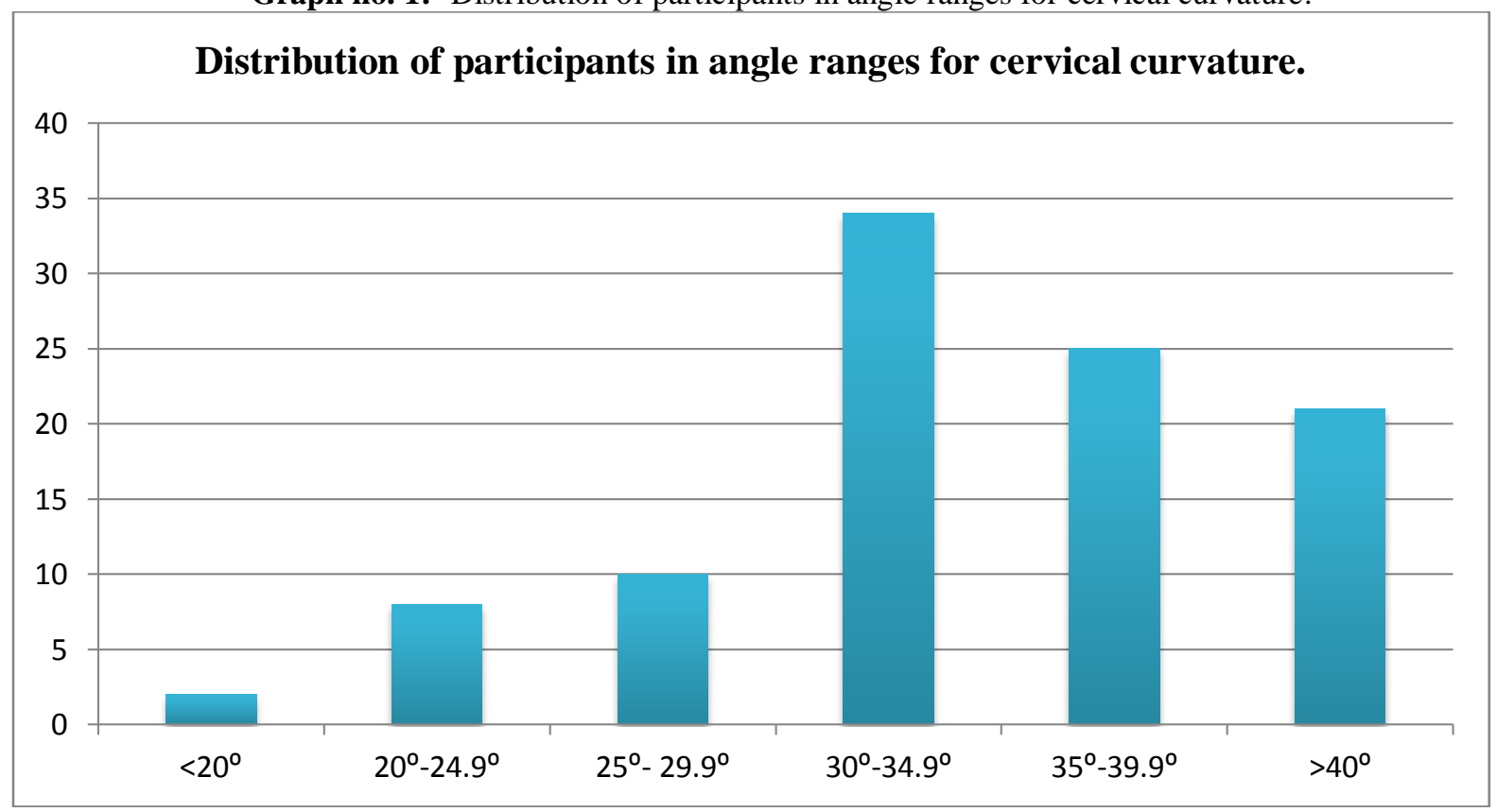


The graph shows that maximum number of participants have cervical curvature between the ranges $30^{0}-34.9^{0}$ which is followed by the angle ranges between $35^{\circ}-39.9^{0}$, both of which are included in the normal cervical curvature.

Table no. 2:- Distribution of participants in angle ranges for thoracic curvature.

\begin{tabular}{|l|l|}
\hline Angle Ranges & No. of participants \\
\hline$<20^{0}$ & 20 \\
\hline $20^{0}-24.9^{0}$ & 17 \\
\hline $25^{0}-29.9^{0}$ & 19 \\
\hline $30^{0}-34.9^{0}$ & 11 \\
\hline $35^{0}-39.9^{0}$ & 28 \\
\hline$>40^{0}$ & 5 \\
\hline Total & 100 \\
\hline Mean angle \pm Standard Deviation & $29.09^{0} \pm 6.32^{0}$ \\
\hline
\end{tabular}

Graph no. 2:- Distribution of participants in angle ranges for thoracic curvature.

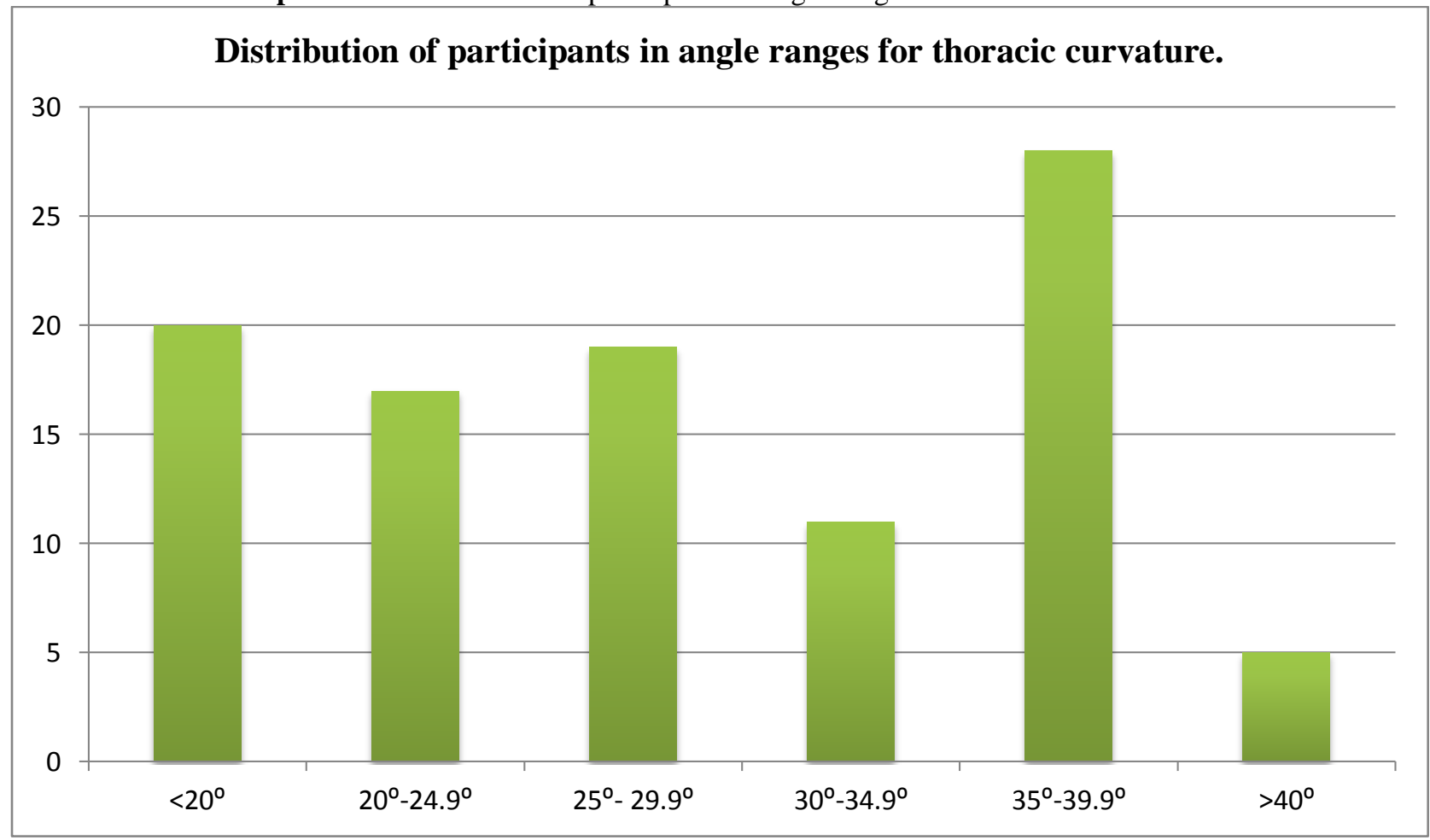

The graph shows that maximum number of participants have thoracic curvature between the ranges $35^{0}-39.9^{0}$ which lies within the normal ranges, followed by the number of participants having angle ranges less than $20^{\circ}$.

Table no. 3:- Distribution of participants in angle ranges for lumbar curvature.

\begin{tabular}{|l|l|}
\hline Angle Ranges & No. of participants \\
\hline$<20^{0}$ & 1 \\
\hline $20^{0}-24.9^{0}$ & 7 \\
\hline $25^{0}-29.9^{0}$ & 11 \\
\hline $30^{0}-34.9^{0}$ & 16 \\
\hline $35^{0}-39.9^{0}$ & 11 \\
\hline $40^{\circ}-45^{\circ}$ & 24 \\
\hline$>45^{\circ}$ & 30 \\
\hline Total & 100 \\
\hline Mean angle \pm Standard Deviation & $39.35^{\circ} \pm 10.59^{\circ}$ \\
\hline
\end{tabular}


Graph no. 3:- Distribution of participants in angle ranges for lumbar curvature.

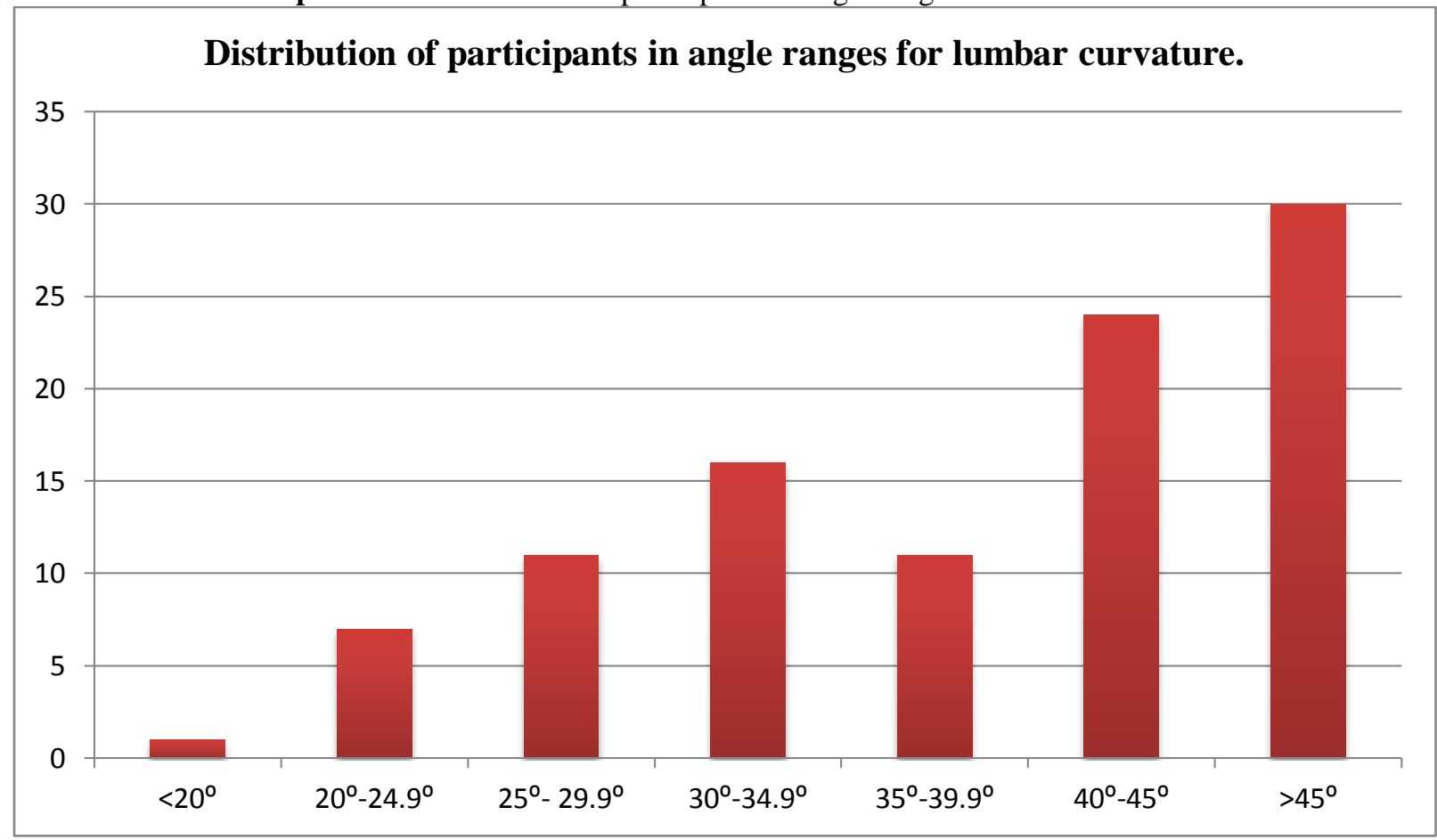

The graph shows that maximum number of participants have lumbar curvature of $>45^{\circ}$, followed by the number of participants having angle between the ranges $40^{\circ}-45^{\circ}$ both of which are more than the normal values for lumbar curvature.

\section{Discussion:-}

This study aimed to identify postural changes that are prevalent in the early ages. The screening covered 100 students aged 6-10 years, 34 girls and 66 boys. The obtained results on the distribution of improper posture and spinal deformities are given in table numbers 1,2 and 3.

The findings from the study revealed that $59 \%$ of the subjects (i.e. 59 out of 100) had normal cervical posture which is between $30^{\circ}-40^{0[10]} .20 \%$ (i.e. 20 out of 100 ) of the subjects had decreased cervical angles and $21 \%$ (i.e. 21 out of 100) of the subjects had increased cervical angle which is forward head. In a study done by Shivani Lalitkumar Verma, Jilani Shaikh, Ranveer Kumar Mahato et al, they have found that the prevalence of Forward head posture is $63 \%$ in Vadodara, Gujarat. ${ }^{[1]]}$

For the curvature of the thoracic spine, the results showed that $75 \%$ of the subjects (i.e. 75 out of 100) had normal thoracic curvature which is between $20^{\circ}-40^{0[12]} .20 \%$ of the subjects (i.e. 20 out of 100 ) had thoracic angle less than $20^{\circ}$ and $5 \%$ of the subjects (i.e. 5 out of 100) had increased thoracic angle of more than $40^{\circ}$. In a study done by Saša Bubanj, Mladen Živković, Dobrica Živković et al, they found that the prevalence of kyphotic bad body posture was $20.8 \%$ in Serbia. ${ }^{[5]}$

The results for the lumbar spine showed that $45 \%$ of the subjects (i.e. 45 out of 100) had normal lumbar curvature which is $20^{\circ}-40^{0[12]} .1 \%$ of the subjects (i.e. 1 out of 100 ) had lumbar angle less than normal and $54 \%$ of the subjects (i.e. 54 out of 100) had lumbar angle more than normal which is lumbar hyperlordosis. In the same study mentioned above, they also mentioned that the prevalence of lordotic bad body posture was $24.2 \%$ in Serbia. ${ }^{[5]}$

The reasons could be increased amount of time spent on mobile phone, abnormal posture while studying, improper school and housing furniture, incorrect use of heavy bag packs, prolonged time spent in front of television screens and computers. In everyday life there are no precautionary actions against spinal deformations. ${ }^{[1]}$ There is a lack of 
physical activity, lack of exercise, irrational nutrition and many other bad habits leading to poor muscle support, obesity, improper posture and spinal deformities. ${ }^{[1]}$

Besides the knowledge about the prevalence of postural change, it is also essential to understand the connection between this prevalence and the environment, in other words, how the daily habits adopted by school children cause postural problems. ${ }^{[3]}$ There is a need to incorporate new public policies in the school environment in order to avoid further progression of the postural changes. Restoration of the practice of creating groups of the correct body posture gymnastics in schools is recommended. ${ }^{[1]}$

\section{Conclusion:-}

This study concluded that cervical spine deformity was prevalent in less than half (41\%) of the subjects whereas deformities in the thoracic spine were prevalent in quarter $(25 \%)$ of the sample size and lumbar spine deformities were prevalent in more than half (55\%) of the subjects.

\section{Limitations:-}

1. The sample size was limited as it was a time bound study.

2. The study could not determine the prevalence of scoliosis in school children.

\section{Future scope of the study:-}

1. To conduct the study on a larger sample size.

2. To conduct the study for longer duration.

3. To conduct the study for prevalence of scoliosis.

\section{Clinical Implication:-}

By identifying the prevalence of the spinal deformities, efforts can be taken to implement the physiotherapy interventions in the early stage in prevention of further spinal deformities.

\section{References:-}

1. Mitova S. Frequency and prevalence of postural disorders and spinal deformities in children of primary school age. Research in Kinesiology. 2015 Jun 1;43(1):21-4.

2. Florence Peterson Kendall, Elizabeth Kendall McCreary, William Anthony Romani. Muscles Testing and Function with Posture and pain. Fifth Edition. 2005.

3. da Rosa BN, Noll M, Sedrez JA, Furlanetto TS, Candotti CT. Monitoring the prevalence of postural changes in schoolchildren. Journal of physical therapy science. 2016;28(2):326-31.

4. Good CR, Auerbach JD, O'Leary PT, Schuler TC. Adult spine deformity. Current reviews in musculoskeletal medicine. 2011 Dec 1;4(4):159.

5. Bubanj S, Živković M, Živković D, Milenković S, Bubanj R, Stanković R, Ćirić-Mladenović I, Stefanović N, Purenović T, Stojiljković D, Obradović B. The incidence of sagittal postural deformities among high school students: preliminary study. ActaKinesiologica. 2012;6(2):27-30.

6. Sedrez JA, Candotti CT, Rosa MI, Medeiros FS, Marques MT, Loss JF. Test-retest, inter-and intra-rater reliability of the flexicurve for evaluation of the spine in children. Brazilian journal of physical therapy. 2016 Apr;20(2):142-7.

7. Singla D, Veqar Z. Methods of postural assessment used for sports persons. Journal of clinical and diagnostic research: JCDR. 2014 Apr;8(4):LE01.

8. Singla D, Veqar Z. Association between forward head, rounded shoulders, and increased thoracic kyphosis: a review of the literature. Journal of chiropractic medicine. 2017 Sep 1;16(3):220-9.

9. Barrett E, McCreesh K, Lewis J. Intrarater and interrater reliability of the flexicurve index, flexicurve angle, and manual inclinometer for the measurement of thoracic kyphosis. Rehabilitation research and practice. 2013;2013.

10. McAviney J, Schulz D, Bock R, Harrison DE, Holland B. Determining the relationship between cervical lordosis and neck complaints. Journal of manipulative and physiological therapeutics. 2005 Mar 1;28(3):187-93.

11. Verma SL, Shaikh J, Mahato RK, Sheth MS. Prevalence of forward head posture among 12-16 year old school going students-A cross sectional study. Applied Medical Research. 2018;4(2):18-21.

12. de Baranda PS, Cejudo A, Moreno-Alcaraz VJ, Martinez-Romero MT, Aparicio-Sarmiento A, Santonja-Medina F. Sagittal spinal morphotype assessment in 8 to 15 years old Inline Hockey players. PeerJ. 2020 Jan 2;8:e8229. 